\title{
Immediate postpartum insertion of intrauterine devices: experience of maternity ward of the university and teaching hospital of Treichville, Abidjan
}

\author{
Privat Yere Guie ${ }^{1}$, Jean Marc Hervé Lamine Dia ${ }^{1}$, Gérard Okon ${ }^{1}$, Telly $\mathrm{SY}^{2}$
}

\author{
${ }^{1}$ Department of Obstetrics and Gynaecology, Treichville Teaching Hospital, Abidjan-Côte d'Ivoire \\ ${ }^{2}$ Department of Obstetrics and Gynecology, Maternity, Ignace Deen CHU de Conakry, Conakry, Guinée
}

Received: 25 July 2016

Accepted: 26 August 2016

\section{*Correspondence: \\ Dr. Jean Marc Hervé Lamine Dia, \\ E-mail: jmlaminedia@yahoo.fr}

Copyright: ( $\odot$ the author(s), publisher and licensee Medip Academy. This is an open-access article distributed under the terms of the Creative Commons Attribution Non-Commercial License, which permits unrestricted non-commercial use, distribution, and reproduction in any medium, provided the original work is properly cited.

\begin{abstract}
Background: In Côte d'Ivoire, where the rate of undesired pregnancies is high, we were the first Maternity centre, to benefit from training on immediate postpartum insertion of intrauterine devices (IUD). The objective of this study is to share our experience and present the results of this practice in our hospital.

Methods: It was a prospective and descriptive cohort study from the $11^{\text {th }}$ of November 2013 to the $30^{\text {th }}$ of April 2016 including the patients who delivered at the maternity of CHU Treichville (University Hospital Centre, Abidjan, Côte d'Ivoire), and had immediate postpartum IUD insertion, with a control 6 weeks later and then 3 months later.

Results: 790 IUD have been, inserted to women with average age and gravidity of respectively 31.3 years old (13-52 years) and 4.4 (1-12 pregnancies). Most of our patients had a low socioeconomic status (poor education: $51.1 \%$; not married: 59.9\%). The counseling occurred during the latent phase of the labour for $57.2 \%$ of the women and the major parts of the IUD $(59,1 \%)$ were insert during a caesarean section. We noticed a poor rate of default patients (14 lost after 3 months), no complications but $9 \%$ of side effects (spontaneous expulsion, missing string). During the follow up period, four patients decided to remove the device. One of them for pelvic pain and three for a non-motivated request of the patients.
\end{abstract}

Conclusions: Our experience shows that on immediate postpartum insertion of IUD is possible in our environment.

Keywords: Contraception, Postpartum, IUD

\section{INTRODUCTION}

The rates of undesired pregnancies (source of abortion) in our developing countries remain high, reflecting the failure of our contraception strategies. One of the strategies recommended by the World Health Organisation (WHO) to reduce this rate is the vulgarization of the immediate postpartum insertion of intra uterine device (IUD). ${ }^{1}$

In Côte d'Ivoire, we were the first maternity centre, to benefit from training on immediate postpartum insertion of IUD. Since this training took place in 2013, we started practicing this method in our unit. The objective of this study is to share our experience and present the results of this practice in our hospital.

\section{METHODS}

The aim was to make a prospective and descriptive cohort study from the $11^{\text {th }}$ of November 2013 to the $30^{\text {th }}$ of April 2016. During this period, we included the patients who delivered at the maternity of $\mathrm{CHU}$ Treichville (University Hospital Centre, Abidjan, Côte d'Ivoire), had immediate postpartum IUD insertion, and a control 6 weeks later and then 3 months later. 
Before the IUD insertion, patients received counseling about contraception during the first stage of labor, or right after delivery. Furthermore, we made sure that patients had no local infection (amniotic liquid infection) and unexplained vaginal bleeding.

We used a T380A copper-bearing device inserted in the uterine fundus by a trained person within the 48 hours for a normal delivery or during the caesarean. The device had to be purchased by the patients and was available at a subsidized amount ( 3 USD instead of 30 USD) at the hospital.

We started an antibiotic prophylaxis (amoxicillin, 1g/day for 5 days by oral route) after the device insertion and the patients are recommended to come back if presenting signs of infection, vaginal bleeding, and feelings of discomfort or pain. Data collection and analysis were made with the Epi Info 5 software.

\section{RESULTS}

\section{Epidemiologic characteristics of the study population}

During the co-optation period, 8792 women delivered in our unit and received counselling. After the counselling, $1260(14.33 \%)$ patients reported already using a contraceptive method before and they choose not to change for the IUD. Among the 7532 left, only 790 $(10.5 \%)$ agreed to have an immediate post-partum IUD insertion.

The average age and gravidity of the women was respectively 31.3 years old (13-52 years) and 4.4 (1-12 pregnancies).

Table 1: Socio demographic characteristics.

\begin{tabular}{|lll|}
\hline Socio demographic characteristic: & Population & \% \\
\hline Age (years) & & \\
\hline$<19$ & 52 & 6.6 \\
\hline $20-29$ & 276 & 34.9 \\
\hline $30-39$ & 361 & 45.7 \\
\hline $40-49$ & 99 & 12.5 \\
\hline$\geq 50$ & 2 & 0.3 \\
\hline Total & $\mathbf{7 9 0}$ & $\mathbf{1 0 0}$ \\
\hline Gravidity & & \\
\hline 1 & 64 & 8.1 \\
\hline $2-3$ & 267 & 33.8 \\
\hline$\geq 4$ & 459 & 58.1 \\
\hline Total & $\mathbf{7 9 0}$ & $\mathbf{1 0 0}$ \\
\hline Parity & & \\
\hline 0 & 19 & 2.4 \\
\hline 1 & 100 & 12.7 \\
\hline $2-3$ & 295 & 37.3 \\
\hline$\geq 4$ & 376 & 47.6 \\
\hline Total & $\mathbf{7 9 0}$ & $\mathbf{1 0 0}$ \\
\hline Living children & & \\
\hline
\end{tabular}

\begin{tabular}{|lll|}
\hline 0 & 24 & 3 \\
\hline 1 & 108 & 13.7 \\
\hline $2-3$ & 333 & 42.2 \\
\hline$\geq 4$ & 325 & 41.1 \\
\hline Total & $\mathbf{7 9 0}$ & $\mathbf{1 0 0}$ \\
\hline Level of education & & \\
\hline None/primary & 404 & 51.1 \\
\hline Secondary & 251 & 31.8 \\
\hline Graduate & 135 & 17.1 \\
\hline Total & $\mathbf{7 9 0}$ & $\mathbf{1 0 0}$ \\
\hline Marital status & & \\
\hline Married & 317 & 40.1 \\
\hline Concubinage & 264 & 33.4 \\
\hline Single & 209 & 26.5 \\
\hline Total & $\mathbf{7 9 0}$ & $\mathbf{1 0 0}$ \\
\hline
\end{tabular}

\section{Insertion process and control}

Table 2: Insertion process and control.

\begin{tabular}{|c|c|c|}
\hline Insertion process and control & Population & $\%$ \\
\hline \multicolumn{3}{|l|}{ Period of counselling } \\
\hline Antenatal visit & 133 & 16.8 \\
\hline Labor time & 506 & 64.1 \\
\hline Post-partum & 151 & 19.1 \\
\hline Total & 790 & 100 \\
\hline \multicolumn{3}{|l|}{ Period of insertion } \\
\hline Post-placental & 164 & 20.8 \\
\hline Immediate postpartum & 159 & 20.1 \\
\hline Per caesarean section & 467 & 59.1 \\
\hline Total & 790 & 100 \\
\hline \multicolumn{3}{|l|}{ Number of follow up } \\
\hline 06 weeks (10 losts of follow up) & 780 & 98.7 \\
\hline 03 months (4 losts of follow up) & 776 & 99.4 \\
\hline \multicolumn{3}{|l|}{ Side effects (after 3 months) } \\
\hline Spontaneous expulsion & 13 & 1.7 \\
\hline Missing string & 45 & 5.8 \\
\hline None & 718 & 92.5 \\
\hline Total & 776 & 100 \\
\hline
\end{tabular}

The control was made at the maternity with $1.8 \%$ (14 patients) lost's of follow up after three months.

During the follow up period, four patients decided to remove the device. One of them for pelvic pain and three for a non-motivated request of the patients.

\section{DISCUSSION}

\section{Epidemiologic characteristics of the study population}

\section{Prevalence of the IUD insertion}

During the study period, on 7532 deliveries of women in need of a contraceptive method, only $10.5 \%$ (790) effectively received the device. This was due to reasons such as the cost of the device that couldn't be afforded 
for a lot of women even if it was State-subsidized, or the non-eligibility of few patients after delivery (fever, hemorrhage). Some patients were also not able to take a decision by themselves and needed to refer to their spouse before.

The use of the IUD immediately after postpartum and per caesarean-section started 30 years ago and was executed in different countries without consensus. ${ }^{2-4}$

In some places were this practice is older with a better managing system, some articles based on most important series were published. Thiery reported a publication based on 2000 patients receiving an immediate postpartum IUD. ${ }^{5}$

\section{Socio demographic characteristic}

We found ourselves with a young population with an average age of 31.3 years and $41.2 \%$ of them were under 30 years. Those patients without contraception could contract undesirable pregnancy and being exposed to risky abortion. Indeed, Vroh J. noticed that in our country, the rate of patients practicing clandestine abortion was higher for less than 30 years. ${ }^{6}$

Moreover, in our study, patients were multigesta (58.1\%) and multiparous $(47.6 \%)$. A new non-controlled pregnancy for this population would be risky. Different authors already reported that pregnancy on multiparous patients could be dangerous. $^{7-9}$

At last, most of our patients had a low socioeconomic status (poor education, 51.1\%; not married, 59.9\%) constituting a risky eligible population for clandestine abortion in case of undesirable pregnancy. Several authors have thus demonstrated in developing countries, that clandestine abortion rate was higher for low socioeconomic patients. ${ }^{6,9,10}$ Sociodemographic characteristics of our population confirmed a real need for contraception and the IUD is a suitable solution.

\section{Insertion process and control}

\section{Periods of counseling}

Three periods are frequently recommended: during the antenatal period, during the latent period of the labour, or within the 48 hours after delivery. ${ }^{1}$ In our study the counseling occurred during the latent phase of the labour for $57.2 \%$ of the women.

In fact, most of the pregnant women didn't have antenatal consultation or were not attending our unit during their pregnancy. They didn't systematically receive counseling about family planning. Contraception have a chance to be accepted without reserve by a woman just after delivery, and the health care centre can provide a good environment for the IUD insertion. ${ }^{2-4}$
However, we often encountered difficulties of comprehension due to the poor education level and the cultural and religious background of our population. We have more than 50 languages in Côte d'Ivoire and some patients are not even speaking French. We had to look for translators among the medical team and it's not always easy to translate some words or expression in vernacular languages. Furthermore, some patients are not able to take a decision by themselves and need to refer to their spouse. Noticed that in our unit husband are not allowed to enter the labor room.

Although many authors declared that counseling in labor room could improve the acceptability of a contraceptive method, we think that the acceptance rate can be improve if the counseling start in antenatal consultation to allowed the spouse to be part of the decision and to deal with the translation factor. ${ }^{2,4}$

But this labor room counseling approach is more suitable for developing countries where delivery is sometimes the only moment for a woman to be in contact with healthcare providers, and the chance of coming back for counseling on contraception method are very poor. ${ }^{1}$

\section{Periods of insertion}

The major parts of the IUD (59.1\%) were insert during a caesarean section. This level is due to our status of third level maternity centre with a high rate of urgently referred patients.

For $20.8 \%$ cases, the insertion was made in ten minutes after the placental delivery which is the recommend time. Some insertions were made later, within 48 hours after placental delivery (20.1\% of cases), for different reasons such as patients in a labor advanced stage on arrivals and the counseling was then postponed after the delivery or trained medical team not available due to other urgent situation occurring. We also had situation of lake of sterilized material.

\section{Follow-up and side effects}

In our series, we noticed a poor rate of patients who default (14 lost after 3 months), no complications but $9 \%$ of side effects.

Missing IUD string (5.8\%) was the most frequent side effect in our study. It is a common situation with patients having IUD inserted during the caesarean section. In this case the ultrasound echography will confirm the presence and the good position of the IUD. ${ }^{11}$ The second side effect was spontaneous expulsion of the IUD found in $1.5 \%$ of our series. O'Hanley shown that the expulsion rate of the post-partum IUD could be very high. It is related to the timing and the technic of insertion. ${ }^{12}$

According to O'Hanley the expulsion's rate is valued between $7 \%$ and $15 \%$ at 6 months, when the IUD is 
inserted by an experienced healthcare worker. ${ }^{12}$ Grimes D. found that the Immediate postpartum IUD have a higher expulsion rate than the late insertion (after 4 weeks). ${ }^{2}$ Many randomized multi-centre studies; found that the difference between the 2 timing was not significant. $^{3,13-16}$

The decreasing of the expulsion rate requires good technical skills during the insertion of the IUD (insertion in uterine fundus with the right instrument, Kelly forceps) and an early follow-up allowing the detection of spontaneous expulsion of the IUD, and the implementation of contraception in order to avoid undesirable pregnancies.

Other complications like infections and uterine perforations were described by the literature. ${ }^{3,5}$ But in our study, we didn't find any infection, due to an early antibiotic therapy and good aseptic practices (disinfection of the reproductive tract) supporting the insertion. The uterine perforations were avoided by the insertions being made by trained members of our unit. ${ }^{12}$

\section{CONCLUSION}

Our experience shows that these practices are possible in our environment and deserved to be scaled up. Furthermore, the socio demographic characteristics of our population confirm a real need for long acting contraception and the IUD device is a suitable solution. We therefore need to find ways to improve the acceptance rate during counselling.

Funding: No funding sources

Conflict of interest: None declared

Ethical approval: Not required

\section{REFERENCES}

1. Rathore AM. Immediate postpartum insertion for intrauterine devices. The WHO Reproductive Health Library ; Geneva : World Health Organization; 2010.

2. Grimes D, Schlz K, Vliet Van H, Stanwood N. Immediate post-partum insertion of intrauterine devices: a cochrane review. Human Reproduction. 2002;17:549-54.

3. Tatum HJ, Beltran RS, Ramos R, Van Kets H, Sivin I, Schmidt FH. Immediate post placental insertion of GYNE-T 380 and GYNE-T 380 postpartum intrauterine contraceptive devices: randomized study. Am J Obstet Gynecol. 1996;175(5):1231-5.
4. Cwiak C, Gellasch T, Zieman M. Peripartum contraceptive attitudes and practices. Contraception. 2004;70:383-6.

5. Thiery M, Van Kets H, Van der Pas H. Immediate post-placental IUD insertion: the expulsion problem. Contraception. 1985;31(4):331-49.

6. Vroh JB, Tiembre I, Attoh-Toure H, Kouadio D E, Kouakou L, Coulibaly L, et al. Épidémiologie des avortements provoqués en Côte d'Ivoire. In Santé Publique HS. 2012;24:67-76.

7. Doumbia Y, Djanhan Y, Kouakou K. Problématique des décès maternels par hémorragie à la maternité de formation sanitaire d'Abobo Sud (ABIDJAN). Rev Int de Sci Méd. 2006;8(2):41-5.

8. Ujah IAO, Aisien OA, Mutihir JT, Vanderjagt DJ, Glew RH, Uguru VE. Factors contributing to maternal mortality in North-Central Nigeria: a seventeen-year review. African Journal of Reproductive Health. 2005;9(3):27-40.

9. Desgrées Du Loû A, Msellati P, Viho I, WelffensEkra C. Le recours à l'avortement provoqué à Abidjan: une cause de la baisse de la fécondité? In Population. 1999;54(3):427-46.

10. Mayi-Tsonga S, Obiang PA, Minkobame U, Ngouafo D, Ambounda N, de Souza MH. Introduction of postabortion contraception, prioritizing long-acting reversible contraceptives, in the principal maternity hospital of Gabon. Int $\mathrm{J}$ Gynecol Obstet. 2014;126(Suppl 1):45-8.

11. Gonzalez JS, Lunde BM, Stimel S, Fishman DA, Thomas AG. Ultrasound surveillance of intrauterine devices placed immediately after cesarean delivery. Obstet Gynecol. 2015;125 Suppl 1:67S.

12. O’Hanley K, Huber DH. Postpartum IUDS: key for success. Contraception. 1992;45(4):351-61.

13. Mishra S. Evaluation of safety, efficacy, and expulsion of post-placental and intra-cesarean insertion of intrauterine contraceptive devices. J Obstet Gynaecol India. 2014;64(5):337-43.

14. Lester F, Kakaire O, Byamugisha J, Averbach S, Fortin J, Maurer R, et al. Intra-cesarean insertion of the Copper T 380 A versus 6 weeks post-cesarean: a randomized clinical trial. Contraception. 2014;91(3):198-203.

15. Washington CI, Jamshidi R, Thung SF, Nayeri UA, Caughey $\mathrm{AB}$, Werner EF. Timing of post-partum intra-uterine device placement: a cost-effectiveness analysis. Fertil Steril. 2015;103(1):131-7.

16. CHI IC, Wilkens L, Rogers S. Expulsion in immediate postpartum insertion of lippes loop D and Copper T IUD's and their counterpart delta devices, an epidemiological analysis. Contraception. 1995;32:119-34.

Cite this article as: Guie PY, Lamine Dia JMH, Okon G, Telly SY. Immediate postpartum insertion of intrauterine devices: experience of maternity ward of the university and teaching hospital of Treichville, Abidjan. Int J Reprod Contracept Obstet Gynecol 2016;5:3349-52. 